\title{
FACTORS INFLUENCING THE SPECIFICATION OF WHEELCHAIRS SUPPLIED BY THE MINISTRY OF HEALTH FOR THE DOMESTIC USE OF INVALIDS
}

\author{
J. WALKer, A.M.I.Mech.E. \\ Chief Technical Inspector, Ministry of Health \\ (Crown copyright: reproduced by permission of The Controller, H.M.S.O.)
}

\section{INTRODUCTION}

You have already been given details of the quantities of Wheelchairs which are 'on issue' from the Ministry of Health for the personal use of the disabled within the framework of the National Health Service. These are purchased at an average annual rate of 13,000 .

They fall generally into the following groups: (a) Folding pushchairs for outdoor use. (b) Rigid wheelchairs for indoor use. (c) Folding transit wheelchairs.

Of these the last is by far the largest group (I0,500 are purchased annually) and creates the most problems. It is no longer accurate to class it as a transit chair because it has become popular as a general purpose wheelchair. This has resulted in its development catering for a variety of special needs and it can accommodate a wide range of fitments. Its weight has therefore increased from an original $36 \mathrm{lb}$. to $56 \mathrm{lb}$. This is a disadvantage to those whose basic requirement is a simple transit chair of minimum weight and having a high degree of manœuvrability. It is on this group of wheelchairs that I have concentrated in this paper.

It is readily apparent that in order to produce wheelchairs in these quantities, it is essential that there should be optimum standardisation. It is not practicable to produce a wheelchair design which meets the needs of a particular disability without regard to the general requirements of the majority of users. What we in the Ministry try to do is to specify a fairly standard design which can incorporate a wide range of fitments to meet, as near as is possible, the requirements of the individual. We do not stop there. When requested we visit hospitals and also make domiciliary visits to assess special difficulties and, where necessary, modify the standard wheelchair, or in exceptional cases design special ones, to meet particular needs.

\section{REQUIREMENTS}

The medical requirements of wheelchairs are outside the scope of this paper. I would list the other general user characteristics as follows: comfort, simplicity, reliability, stability, manœuvrability,-small bulk and weight, good appearance, low cost. I would now like to consider these in detail.

Comfort. Naturally this must be considered first, but I feel that it is relative to the purpose for which the wheelchair is intended.

The most severely disabled who are immobile will require maximum comfort. Those who have relatively strong upper limbs will need to sacrifice some degree of comfort if they are to maintain independence and manœuvrability.

Simplicity. It is implicit in good design that it should be as simple as the functional requirements will allow. The user should be able to see and know what 
his wheelchair is doing. This engenders confidence. The wheelchair must be easy to clean and to maintain. Faults and defects should be readily observed so that they can be removed before they let the user down in critical circumstances.

Reliability. This is axiomatic and should not require exposition. Failures can be dangerous and we know of cases where patients have been injured as a result of these. Ideally, wheelchairs should require no attention during their service life. Maintenance and adjustments must be kept to a minimum. The user can rarely do this himself and suitable labour is not often available at short notice. Breakdowns immobilise the user, may occur in critical circumstances and put him in a helpless position.

Stability. Manœuvrability and overall dimensions limit the extent to which one can go in this direction. Present-day wheelchairs are relatively stable providing the user knows what he is doing and appreciates the limits to which he can go. The lighter the wheelchair becomes, the greater the difficulty in giving stability. However, it is a point which must always be given attention.

Manœuvrability. It is essential that the wheelchair should be able to negotiate confined spaces, through doorways and around the home and workplace. There will always be a conflict between the user's personal requirements and the need to fit the wheelchair into an everyday environment. There is little object in giving him a wheelchair which cannot be taken into all the places he will want to visit.

Small Bulk and Weights. The overall dimensions must be as small as possible for a given seat size. The average doorway is 28 inches wide. With a seat width of 17 inches and an overall width of 25 inches there is only a clearance of $I \frac{1}{2}$ inches on each side of the wheelchair. Most doors open on to narrow passageways and so the turning radius must be kept to a minimum. It must fold so that it can be stowed in an invalid tricycle and we specify a maximum of Io inch width when folded. It must also fit between the front and rear seats of motor cars so that a user can enter the vehicle and stow the wheelchair unaided. The height and length should also be such that they permit it to be stowed in a car luggage-space. All this manhandling requires that the weight should be kept to a minimum. Probably a minimum weight of $36 \mathrm{lb}$. can be achieved for a lightweight transit chair without sacrificing strength.

Good appearance. It is not possible to disguise two large wheels and two castors without adding weight and complexity. A wheelchair must be functional, but appearance can be improved by the use of tube work having flowing lines rather than being a mass of straight fabrications. Pleasing colour conbinations can be used and it is interesting to note that in the Ministry we no longer specify black as an alternative colour.

Low Cost. This is obviously more important to the Ministry than to the user. However, we should not lose sight of the fact that Ministry requirements influence the general design in the private market and a policy which aims at low cost in relation to simplicity, reliability, etc., is one which is of benefit to all users.

Cost is allied to production rates and these are adversely affected if special 
features are specified on a bespoke basis. What is perhaps not so readily appreciated is the value of interchangeability as a derivative of standardisation. It is well worth considering that it might be better to give the user a wheelchair which does not meet his exact requirements rather than to fit him up with something which is very special and cannot be replaced at short notice if it breaks down or needs to be withdrawn for re-working. There are obviously limits to which such a policy can be taken. There will always be a small percentage of users who are special and need custom built wheelchairs which cannot be used by others.

\section{TECHNICAL FEATURES}

I would now like to discuss briefly the various special assemblies which comprise a transit-type wheelchair and some of the technical considerations involved.

Dimensions. The seat is 19 inches from the ground and the footrest is infinitely adjustable from 13 inches to 17 inches below the seat. The overall height is 38 inches and the overall length $4 \mathrm{I}$ inches. The folded width is Io inches.

Wheels and handrims. It could be said that in a wheelchair the wheels and castors serve to replace the lower limbs. Since they are not able to signal to the body an indication of the overload imposed upon them, they are often badly treated. They are the source of mobility and must therefore be the most reliable members of the wheelchair. This applies equally of course to the castors. Wheels, handrims and castors represent about 45 per cent by weight of the wheelchair.

We currently specify an adjustable ballbearing alluminium alloy hub with 28 spokes of 12 s.w.g. diameter. It is preferable to have a tyre which can easily be renewed. Although we have previously specified solid rubber tyres, we are now providing pneumatics as well. This effects a weight saving of $5 \mathrm{lb}$. on the wheelchair. Pneumatic tyres were criticised because they needed regular inflating, but modern non-porous inner tubes and better valves have overcome this and such tyres should not require inflating more than two or three times a year. There is of course the danger of punctures, but we feel that the risk is worth taking because of the weight saving and additional comfort when traversing rough surfaces. We specify a wheel of 22-inch diameter because we feel that this is a fair compromise having regard to bulk and the need to enable some patients to enter their wheelchairs sideways.

Wooden handrims were used until recently bacause metal is cold to the touch, The disadvantages of wooden rims is that they easily splinter if knocked. Currently nylon coated-steel tubing is used and there is probably a field for developing all plastic rims. The use of an aluminium alloy extrusion or plastics which would combine wheel and handrim is probably worth examination.

Castors. These should be as large as is practicable in order to keep the effort required as low as possible and to assist in negotiating thresholds, rugs and other obstacles. We favour a minimum of 7 -inch diameter. They should run on ball or needle bearings which should be reasonably well sealed to exclude grit.

We specify solid rubber tyres and it is essential that they should be easily replaceable. A hard user can wear out a set of tyres within a few months. There 
is perhaps scope here for the development of synthetic materials which are resistant to wear and cutting.

We now consider that the expanding-sleeve method of securing castors to the wheelchair is unsatisfactory because if they are not properly fitted they can be very dangerous. We favour a positive method of fixing.

Footrest. Because of the need to maintain a high degree of manœuvrability, it is necessary that the footrest should be in front of the castors. This means that it becomes the limiting factor on the turning radius and must therefore be kept to a minimum length. To enable the user to enter the wheelchair, it must fold out of the way. It is common practice to divide the footrest and fold it upwards. Another method is to swing each section outwards which has the advantage of reducing overall length. Whatever method is used, it must be quick and simple to operate.

Seat and Backrest Materials. We have progressed during the years from canvas to plastic-covered canvas materials, but these are not entirely satisfactory and we are investigating alternatives. Seat materials must be very strong and the rate of sag should be kept to a minimum. I think that we still have a long way to go in this direction to achieve a really satisfactory material. We should also aim at providing materials which can easily be removed for cleaning domestically.

Brakes. It is essential that brakes are provided to prevent the chair 'running away' when the patient is getting in or out. Both large wheels should be braked to prevent the wheelchair turning when the patient is getting out or in. The brake can be operated by a lever on one side with cable operation to the opposite wheel so that both brakes are applied simultaneously. Alternatively, two independent brakes can be fitted, each being operated by a separate handle. There is room for improvement in both the efficiency and reliability of brakes.

Extras. I said earlier that we try to specify a standard design which can incorporate a wide range of fitments. We contract for the incorporation during manufacture of:

Propelling wheels at the front instead of at the rear.

Backrest set back $20^{\circ}$ or $25^{\circ}, 20$-inch or 24 -inch diameter wheels fitted with pneumatic tyres. Separately operated brakes to each wheel.

Swinging detachable footrests. One arm control.

The following items can be supplied after delivery:
Extending footrests.
Gantry for arm sling.
Domestic armrests. Feeding or work tray.
Adjustable legrests.
Latex foam cushions.
Backrest or headrest extensions.

These are the main extras, but other minor details can be supplied. When other needs are brought to light, we either place special orders with manufacturers or arrange for modifications to the standard wheelchair to be made locally under our supervision. We do not stop before the user has been given every consideration. Although we have running contracts with manufacturers, wheelchairs (other than 
those going into store) are ordered individually to meet the needs of particular patients. They are then delivered direct to the patient along with any of the extras which are required. This list of extras has been compiled to meet the needs of almost all potential users. It is added to as necessary when new requirements become apparent.

\section{FUTURE DEVELOPMENTS}

Although much has been said in the past about the features which wheelchairs should possess, little information has been correlated which can be used in assessing design requirements. I hope that this Symposium will give guidance in this direction. There is always the danger of taking a parochial view of the needs of particular disabilities, to the exclusion of all others. The broadest possible view must be taken if bulk purchasing is to be considered.

A large part of the designer's problems in meeting the user's requirements is knowing what these requirements really are. The user is not always the best judge of what these should be. What is perhaps necessary is an analysis of a representative number of users. Such an exercise would need to carried out by people who have their feet firmly on the ground and who appreciate how far the designer can go with materials within the acceptable limitations of weight and cost. Often those who seek to lay down the requirements of the ideal wheelchair demand conflicting features which neglect considerations of weight and bulk. A wheelchair produced to these requirements would certainly be unacceptable to the user. It is useless to give him a wheelchair which meets his absolute requirements, if he is never going to be able to use it because it will not fit his everyday environment.

Lightweight Transit Wheelchair. During the past two years there has been a growing demand for the 'car chair'. This is a relatively lightweight wheelchair having small wheels and castors and a low height or removeable extension backrest. It can be folded and the backrest removed as necessary so that it can be stowed in a car boot, hence its name. It cannot be propelled by the occupant, which is, of course, a disadvantage in many circumstances. It seems to meet the needs on the one hand of families having an invalid member and a car to take him out in, and on the other hand those who require an extremely lightweight wheelchair in which to push an invalid who has not the ability to propel himself. This wheelchair seems to fulfil a need which falls between the outdoor folding push chair and the self-propelled transit wheelchair. There is evidently a field for what can be regarded as casual users where the requirements of the attendant take precedence over those of the user.

These factors emphasise the need for a lightweight folding wheelchair which can be obtained either with propelling handrims or small wheels. We have examined alternative methods of propulsion but always return to the handrim method because of its simplicity, reliability and low weight. I think that it will stay with us for many years to come. I have said earlier that the wheels and castors must be inherently reliable and therefore little weight can be saved in this direction, once pneumatic tyres have been fitted. It is in the framework that the major saving must be made. The number and size of its members must be kept to a minimum. This means a short backrest, small fixed armrests (or none at all) and simplified footrests. In this way, an overall weight of 30/35 lbs. may be achieved. 
It will mean that there will be little refinement and it must be designed to meet the fundamental requirements of a transit user, that is to take him from home to his transport and to be such that it can easily be carried with him.

Weight saving may be achieved by the use of alternative materials for the framework. Currently, mild steel solid drawn tubing is favoured. It has the advantage of ease of manipulation and, what is perhaps not readily appreciated, it lends itself to fabrication locally when adaptations are required to meet the needs of special cases after the wheelchair has been manufactured. In contrast, high tensile aluminium alloys are not suitable for this kind of treatment. If aluminium is to be a serious contender in this field, different techniques will need exploiting. It may be worth examining the possibility of diecasting the framework in a few major components but such tooling costs are high and can only be economical when large quantities are produced. The use of plastics and perhaps glass fibre reinforced plastic materials should not be overlooked.

\title{
5. CONCLUSIONS
}

The wheelchair has developed through evolution. In the Ministry we have always been conscious of changing demands and have attempted to anticipate them. Sometimes we have been caught out because there are occasionally fashion changes which, unfortunately, do not seem to be dictated by the physical requirements of invalids. I have attempted in this paper to outline some of the factors which require consideration to enable a satisfactory wheelchair to be evolved which lends itself to bulk production methods and will meet the needs of the majority of invalids. I think there is still a long way to go. It is perhaps in the direction of new materials and techniques that the major advances will be made.

\section{WHEELCHAIRS FOR PARAPLEGICS}

\author{
By J. J. WaLsh, M.D. \\ Deputy Director, National Spinal Injuries Centre, \\ Stoke Mandeville Hospital, Aylesbury, Bucks
}

AN affliction of the spinal cord, whether due to injury or disease, can give rise to the disability known as paraplegia. If the lesion is in the upper part of the cord, that is in the neck, then the upper limbs are also affected and these patients are called tetraplegics or quadriplegics. When the cord lesion is complete, the disabled person not only has paralysis of all skeletal muscles supplied from the cord below the level of the lesion but has also lost all sensory appreciation over a corresponding area. Moreover, he has lost control of bladder and bowels. After the first few weeks following onset, the paralysis may be flaccid or spastic, and the degree of spasticity varies from patient to patient. As a general rule, the lower lesions (below the IIth or I2th thoracic segment) are flaccid and lesions above this level spastic. The sensory loss results in a tendency to develop pressure sores if insensitive areas are subjected to prolonged pressure and also impairment of the patient's balance.

Some patients with incomplete cord lesions and very low lesions do not 